\title{
药 \\ APRESENTAÇÃO DO DOSSIÊ: AÇÕES LEGISLATIVAS E ENFRENTAMENTO À PANDEMIA DE COVID-19
}

\author{
Luciana Santana ${ }^{1}$ \\ Helga Almeida ${ }^{2}$ \\ Fátima Anastasia ${ }^{3}$
}

No ano de 2020 uma crise sanitária mundial se abateu sobre todos. A pandemia do Covid-19 se alastrou pelo planeta e com ela vieram grandes desafios para os governos, instituições e organizações nacionais e internacionais. O primeiro caso de infecção pelo novo coronavírus foi registrado na cidade de Wuhan, na China, em dezembro de 2019. A partir daí, os governos - uns mais, outros menos - começaram a acompanhar a evolução dos casos e a se preparar para o que viria a posteriori.

A crise do novo coronavírus, que somente foi categorizada como pandemia pela Organização Mundial da Saúde em 11 de março de 2020, gerou graves problemas de políticas públicas, amplificados por questões de gestão da saúde, por crises econômicas e pelo esgarçamento do tecido social de diversos países. Nesta conjuntura crítica, governos e demais poderes públicos tiveram que dar respostas assertivas e rápidas para adequar seus sistemas de saúde aos desafios do novo contexto, e para preservá-los, com o objetivo de evitar a propagação do vírus e minimizar os riscos de mortes causados pela Covid-19.

Para a concretização das ações de enfrentamento à pandemia nos Estados democráticos, uma requisição central foi colocada, ainda nos primeiros momentos, às instituições e atores políticos: a necessidade de coordenação horizontal e vertical. Dessa forma, Estados tiveram que lançar mão de suas Constituições, costurar planos, entre-poderes e intra-poderes, e definir estratégias para solucionar diferentes questões advindas da crise em curso.

\footnotetext{
${ }^{1}$ Luciana Santana - Doutora em Ciência Política pela Universidade Federal de Minas Gerais. Professora de Ciência Política na Universidade Federal de Alagoas - UFAL e do Programa de Pós-graduação em Ciência Política na UFPI. Orcid: https://orcid.org/0000-0002-0203-1594. E-mail: lucianacfsantana@yahoo.com.br

2 Helga Almeida - Doutora em Ciência Política pela Universidade Federal de Minas Gerais. Professora na Universidade Federal do Vale do São Francisco - UNIVASF. Orcid: https://orcid.org/0000-0001-7245-4288. E-mail: helgaalmeida@gmail.com

${ }^{3}$ Fátima Anastasia - Doutora em Ciência Política (Ciência Política e Sociologia) pelo Instituto Universitário de Pesquisas do Rio de Janeiro (1992). Foi professora do Departamento de Ciência Política da Universidade Federal de Minas Gerais no período compreendido entre 1988 e 2009 e professora voluntária - aposentada da mesma universidade (UFMG) até 2018. Atualmente é professora adjunto IV da Pontifícia Universidade Católica de Minas Gerais. Orcid: https://orcid.org/0000-0001-5839-9155. E-mail: fatima.anastasia@ gmail.com
} 
Essa articulação demandou que representantes eleitos, burocratas e cidadãos construíssem rapidamente estratégias e projetos no âmbito das políticas públicas de saúde, de proteção social, educação, trabalhista, dentre outras, com os objetivos de distribuir recursos orçamentários, humanos e insumos médicos para o atendimento à população. A capacidade de iniciativa dos líderes dos Executivos, a sintonia entre os poderes e a confiança dos entes subnacionais no caminho escolhido pelo chefe do Poder Executivo foram variáveis importantes na condução desta crise.

No que se refere ao caso brasileiro, vale assinalar a inação e a omissão do Poder Executivo Nacional na gestão da pandemia. Ademais da postura negacionista - é só uma gripezinha - e do comportamento irresponsável de prescrever medicamentos sabidamente inócuos ou prejudiciais no combate ao vírus, no auge da crise, o governo achou por bem cortar verbas e leitos públicos, desincentivar a vacinação e desdenhar do sofrimento que se abateu sobre mais de 200 mil famílias que perderam seus entes queridos, demonstrando uma insensibilidade que não encontra paralelo em outros líderes mundiais, independentemente de suas persuasões políticas e ideológicas.

No espaço vazio deixado pelo Poder Executivo nacional, outros atores ocuparam a cena e ganharam protagonismo, como os governos subnacionais e o Poder Legislativo, nos níveis federal, estadual e municipal. Sua assertividade foi exercida na cobrança de ações e de procedimentos para viabilizar respostas rápidas do governo à pandemia, bem como na criação de inovações institucionais, como o sistema remoto de tomada de decisões, visando garantir o funcionamento das instituições legislativas no contexto adverso gerado pela pandemia.

Após um ano de pandemia, pode-se identificar um amplo espectro de padrões de atuação das diferentes casas legislativas brasileiras, com a predominância de duas tendências: na primeira, encontra-se um Legislativo mais passivo, por contraste com um chefe do Executivo mais atuante, responsivo e comprometido em seguir as recomendações da comunidade científica e das organizações de saúde. Nesse contexto, o Legislativo assumiu as prerrogativas de estar atento às iniciativas do líder do Executivo, trabalhar para a celeridade do processo, dada a urgência das medidas, e fiscalizar suas ações. Uma segunda tendência engloba os legislativos com maior protagonismo, em situações de inação de chefes do executivo na tomada de decisões, abrindo espaços para que lideranças parlamentares ocupassem vácuos tanto em relação à atividade legislativa, quanto no que se refere à comunicação acerca dos protocolos a serem seguidos pelos cidadãos.

Este dossiê especial, intitulado Ações legislativas e enfrentamento à pandemia de Covid-19, contém análises sobre legisladores e legislativos, suas decisões, suas ações e sua interação com outros poderes no enfrentamento da pandemia de Covid-19. O volume reúne quinze artigos escritos por pesquisadores brasileiros e estrangeiros, selecionados a partir de uma chamada pública e de um processo de revisão cega por pares. Além disso, foram realizadas duas 
entrevistas com especialistas em estudos legislativos.

Para facilitar a leitura e a compreensão de todo o dossiê, ele está organizado em quatro seções de artigos e uma seção, que fecha o volume, contendo as entrevistas com os nossos convidados.

A primeira seção apresenta cinco artigos relacionados ao processo decisório e à produção legislativa na Câmara dos Deputados e no Senado Federal brasileiros. O primeiro texto desta seção, de autoria de Lucio Rennó e Andeliton Soares, intitulado Todos pela popularidade: como o apoio popular do Presidente é capaz de afetar o posicionamento dos parlamentares brasileiros, analisa as posições de deputados e senadores em relação ao enfrentamento da pandemia, matizado pela ideologia dos partidos e por sua proximidade com o governo federal. $\mathrm{O}$ artigo "Repertórios de ação dos parlamentos digitais durante o enfrentamento da pandemia", dos pesquisadores Sérgio Braga e Fernando Wisse, busca mapear os repertórios de ação de enfrentamento da Pandemia pelos parlamentos digitais brasileiros, com destaque para sua atuação nas mídias digitais, especialmente o Facebook. Os principais resultados apontam para uma intensa atuação dos parlamentos digitais efetuando ações durante a Pandemia, especialmente nas mídias sociais. Cristiane Corrêa Batista e Fabiano Guilherme Santos, autores do artigo "Origens e implicações do funcionamento congressual em tempos de pandemia notas sobre o sistema de deliberação remota (SDR) e o papel das novas tecnologias", têm por objetivo descrever o micro processo decisório que viabilizou a retomada das atividades de plenário da Câmara tão rapidamente. Através de respostas a questionários semiestruturados, aplicados a atores chaves no processo, Batista e Santos mostram que o investimento prévio em tecnologia e em informação dotou o parlamento de autonomia, garantindo a manutenção de suas atividades durante a pandemia.

A análise sobre o papel das emendas orçamentárias dos parlamentares brasileiros no combate à Covid-19 é o tema do artigo de Raul Wesley Leal Bonfim, Vítor Eduardo Veras De Sandes-Freitas e Bruno De Castro Rubiatti. Os autores analisaram as emendas individuais e de bancadas estaduais aprovadas pelo Congresso Nacional e pagas pelo Executivo entre os meses de março e setembro de 2020. Os resultados indicaram que os legisladores não apenas realocaram suas emendas para as ações indicadas pelo governo, mas, também, que destinaram esses recursos para a execução orçamentária do Ministério da Saúde nos primeiros meses da pandemia no Brasil.

O último artigo da primeira seção é de autoria de Barbara Tayanne Oliveira da Silva, João Vitor Costa e Adrián Albala. Intitulado "Legislar em tempos de pandemia: como a Covid19 tem impactado a produção dos senadores brasileiros?". Este texto afirma que, além de não ter produzido efeitos negativos sobre a produção legislativa, a pandemia parece ter tido um impacto positivo tanto no volume (quantidade) de propostas apresentadas, quanto na celeridade em aprovar as propostas. Segundo os autores, o teor (qualitativo) das propostas também foi 
impactado por um incremento significativo das propostas relativas ao tema da saúde.

Duas experiências internacionais são objetos das análises da segunda seção. Nos dois artigos, os autores examinam o protagonismo do Poder Legislativo, no nível nacional, no que se refere ao combate à pandemia do Coronavírus. Daniel Chasquetti é o autor do texto intitulado Adaptación y consenso: el parlamento uruguayo en la pandemia del coronavirus, que examina a intensa atuação do parlamento do Uruguai durante a crise pandêmica e o consenso estabelecido pelos partidos políticos na arena legislativa, em relação às medidas de saúde, especialmente no que se refere ao isolamento social. No artigo Acciones legislativas para enfrentar la pandemia covid-19 en la República Dominicana, Araceli Mateos e Ana Belen Benito investigaram o Congresso Nacional da República Dominicana, incluindo a Câmara dos Deputados e o Senado, analisando suas ações normativas e fiscalizadoras no contexto da pandemia do coronavírus.

A terceira seção contém artigos que apresentam análises e discussões sobre ações emergenciais apreciadas no âmbito legislativo e sobre oportunidades para ação de grupos de interesses. O primeiro artigo aborda o protagonismo do Congresso Nacional relativamente ao tema da ajuda emergencial. A partir da análise de projetos de lei, emendas e debates parlamentares, Sérgio Simoni Jr, Hellen Guicheney e João Lucas Sacchi Oliveira argumentam que não se pode tomar o Congresso como um ator unitário. Antes, as deliberações revelam disputas ideológica-partidárias com implicações distributivas e, por conseguinte, disputas para a construção de bandeiras eleitorais.

Já a autora Ana Luíza Matos De Oliveira, em seu artigo "Auxílio emergencial na pandemia da covid-19: atuação do Legislativo para a redução de vulnerabilidades", busca enfocar a atuação do legislativo para a aprovação do auxílio e a situação de vulnerabilidade dos trabalhadores brasileiros, antes e durante a crise sanitária no país. O artigo "Covid-19, janelas de oportunidade e políticas para mulheres: análise sobre projetos de lei apresentados no Congresso Nacional", de autoria de Vinícius Ferreira Baptista, analisa os projetos de lei apresentados no Congresso Nacional entre março e maio de 2020, no que se referem às políticas de enfrentamento à pandemia direcionadas para mulheres.

A quarta seção compreende artigos sobre ações e produções legislativas no âmbito subnacional. Murilo de Oliveira Junqueira, autor do artigo "Nem localistas nem setorialistas, as assembleias estaduais são 'classe-médistas': ganhos e perdas das leis estaduais durante a crise da covid-19", analisa o conteúdo das leis aprovadas pelas assembleias legislativas estaduais no combate à crise econômica e social gerada pela Covid-19.

$\mathrm{O}$ artigo " $O$ Legislativo e as oportunidades de participação online sobre a pandemia do coronavírus: o abismo entre as iniciativas dos parlamentos em nível federal e estadual, escrito por Tatiana Güenaga Aneas, Samuel Barros e Juliana Marinho, examina as iniciativas digitais de participação promovidas pelas casas legislativas brasileiras, em nível federal e estadual, em 
resposta à pandemia provocada pela Covid-19 (Sars-CoV-2).

As ações de enfrentamento à pandemia nos estados do Pará e do Amazonas é o tema tratado por Rodolfo Silva Marques e Breno Rodrigo Messias. Os autores concluem que o poder legislativo estadual buscou adotar ações rápidas para o combate à crise, com uma relação mais equilibrada entre Executivo e Legislativo no Pará e conflitos entre os dois poderes no Amazonas.

Maria Paula Escobar Bins, Lidia Nicole Ten Cate, Lucas Dos Santos Giacomel, Pedro Cemim, Sara Sousa e Stephani Schuetz assinam o artigo "Pandemia de covid-19 no Rio Grande do sul: O choque exógeno gerou mudanças na ação do poder Legislativo?". Os autores analisam a atuação legislativa relativamente à pandemia, a partir do conteúdo das proposições em tramitação na Assembleia Legislativa do Estado do Rio Grande do Sul (ALRS) e buscam identificar padrões de taxas de sucesso e áreas de proposição em relação aos projetos. Já o artigo intitulado O federalismo e poder legislativo na pandemia de covid-19: a atuação da assembleia legislativa do Paraná no enfrentamento ao novo coronavírus, de autoria de Eduardo Soncini Miranda e Roberta Picussa, aborda o esforço institucional e as ações da Alep durante a crise trazida pelo Coronavírus.

A quinta e última seção é composta por duas entrevistas. A primeira entrevista foi feita com Fernando Limongi e tratou das ações e das omissões do governo federal no enfrentamento da pandemia de covid-19 no Brasil, bem como das relações entre os poderes Executivo e Legislativo relativamente ao tema. Luciana Santana e Helga Almeida conduziram essa entrevista. A segunda entrevista foi concedida por Sabino José Fortes Fleury a Fátima Anastasia, Luciana Santana e Helga Almeida. Seu tema foi a atuação dos legislativos subnacionais no enfrentamento da Covid-19, destacando a atuação da Assembleia Legislativa de Minas Gerais.

A publicação deste dossiê ocorre em um contexto muito instigante da política brasileira. A eleição para novos presidentes da Câmara dos Deputados e do Senado Federal, em fevereiro de 2021, expressa uma nova correlação de forças no interior das duas casas legislativas e uma tentativa de organizar uma coalizão governativa, capitaneada por setores do Centrão, supostamente destinada a dar apoio ao governo Bolsonaro. Uma dúvida que se coloca refere-se a quem, afinal das contas, governará o país: Bolsonaro? O Centrão? Ambos? Nenhum dos dois? A ver! Outra pergunta que não quer calar é como é possível emergirem dessas eleições para presidentes da Câmara e do Senado duas Casas governistas, em um contexto de crise de governabilidade e de governança? Ou seja, em um contexto de desgoverno. Finalmente, cabe, ainda, perguntar, quais desafios espreitam os cidadãos brasileiros, considerando a persistência e o agravamento da pandemia, a crise econômica, a emergência social e, especialmente, a crise representação democrática que assola o país. 
Nossos agradecimentos a todas as pessoas e instituições que cooperaram para a realização deste dossiê. Obrigado aos autores e aos pareceristas dos artigos. Obrigada aos nossos entrevistados. Obrigada, especialmente, a Antônio Barros, e em seu nome, à Câmara dos Deputados do Brasil e ao periódico E-Legis, por todo o suporte dado durante a produção deste volume.

Boa leitura! 